\title{
Phytoplasma detection in coconut palm and other tropical crops
}

\begin{abstract}
Phytoplasmas are small bacteria with very small genomes which also have extremely low levels of the nucleotides guanine plus cytosine $(\mathrm{G}+\mathrm{C})$. They are associated with hundreds of plant diseases globally. The uneven distribution and low concentration of phytoplasmas in the phloem of infected plant, especially in woody hosts, and variations in titre according to season and plant organ are also important obstacles for efficient diagnosis. Polymerase Chain Reaction (PCR), nested PCR and real-time PCR have been employed for phytoplasma detection. PCR is the most versatile tool for detecting phytoplasmas in their plant and insect hosts. Nested PCR with a combination of different universal primers can improve the diagnosis of unknown phytoplasmas present with low titre in the symptomatic host. Universal ribosomal primers nested with group-specific primers are extremely useful when the phytoplasma to be diagnosed belongs to a well-defined taxonomic group. Real-time PCR has been shown to be an effective method of quantifying the titre of phytoplasmas within the plant. This paper also discuss phytoplasma diseases on coconut palm.
\end{abstract}

Keyword: Coconut yellow decline; Bermudagrass white leaf; Lethal yellowing. 